\title{
AMÉRICA LATINA EM ALGUNS ITINERÁRIOS E CRUZAMENTOS: ENTRE A LETRA E A TELA. LITERATURA, IMPRENSA E CINEMA NA AMÉRICA LATINA (1896-1932), DE MIRIAM GÁRATE ${ }^{1}$ LATIN AMERICA IN SOME JOURNEYS AND INTERSECTIONS: ENTRE A LETRA E A TELA. LITERATURA, IMPRENSA E CINEMA NA AMÉRICA LATINA (1896-1932), BY MIRIAM GÁRATE
}

\section{Hernán Morales}

\author{
Universidad Nacional de Mar del Plata
}

Mar del Plata, Argentina

\begin{abstract}
Yo evito el testimonio real, porque me desagradan los confesionarios y esa objetividad eclesiástica del periodismo acusete. Pero tampoco podría negar mi origen y lo evoco en la escritura, travestido, multiplicado en un tornasol engañador. La verdad no me interesa: es paja estancada y filosófica. Como dice Serrat: la verdad no tiene remedio.
\end{abstract} (LEMEBEL In: SCHAFFER, 1998, p. 58)

(...) Deve ser coisa importante, pois ouvi a campainha tocar várias vezes, uma a caminho da porta e pelo menos três dentro do sonho. Vou regulando a vista, e começo a achar que conheço aquele rostro de um tempo distante e confuso. Ou senão cheguei dormindo ao olho mágico, e conheço aquele rosto quando ele ainda pertencia ao sonho. Tem a barba. Pode ser que eu já tenha visto aquele rosto sem barba, mas a barba é tâo sólida e rigorosa que parece anterior ao rostro. (BUARQUE, 1991, p. 7)

Em um artigo publicado sob o título de La crónica, una mirada extrema ${ }^{2}$, que poderia servir como preâmbulo a esta resenha, Martín Caparrós reflete sobre esse gênero que complexifica náo somente a literatura - mas as artes em geral - e em especial a literatura latino-americana, em função de tensóes e desencontros da Modernidade. América é crônica, sustenta Caparrós, vinculando seu olhar a tensóes assinaladas por Cornejo Polar, Rama, Pizarro e Santiago

1 Resenha de: GÁRATE, Miriam. Entre a letra e a tela. Literatura, imprensa e cinema na América Latina (1896-1932). Rio de Janeiro: Papéis Selvagens, 2017.

2 Em: <http://www.lanacion.com.ar/943086-la-cronica-una-mirada-extrema>. 
a propósito de um espaço de definição que alterna a adaptação entre o conhecido e o não-conhecido, evidenciando matrizes conflituosas. A crônica é um exercício recorrente de estranheza que marcou o processo identitário dos habitantes destas latitudes. Por isso as vozes que nela se manifestam "não mostram mas, antes, evocam, refletem, constroem, sugerem", gerando um estado de crise. Trata-se de textualidades polimorfas que evidenciam as vantagens de recriar modos de contar e formas singulares de perceber o entorno, em um exercício que tem a intenção de "despertar" o leitor. São discursos nos quais o olhar se detém em um objeto configurado como busca, porque a escrita converte-se numa prática dos limites que transcende o foco jornalístico e consegue trazer para o primeiro plano o que normalmente fica oculto, o que não se vê à primeira vista e necessita ser nomeado. Parece tratar-se de uma reinvençáo do espaço latino-americano que em alguns narradores contemporâneos (como Alma Gillermopietro, Elena Poniatowska, Juan Villoro, Pedro Lemebel, Carlos Monsiváis, entre outros), torna-se uma obsessão, marcada pelo exercício político que supóe a confrontaçáo entre o sujeito e seu entorno.

Por essa razão, não é estranho que Miriam Gárate recorra ao liminar expresso pela preposiçáo "entre", com o objetivo de estudar as relaçóes fundadoras do cinematógrafo com a literatura e a imprensa na América Latina, propondo um olhar que se debruça sobre as crônicas que circularam no México, no Chile, no Brasil, no Peru e na Argentina, entre outros países, em finais do século XIX e princípios do XX. Ao longo de mais de 200 páginas, a autora oferece, por meio de uma ensaística impecável, sustentada com grande rigor crítico, uma abordagem das relaçôes imbricadas no discurso de recepção do cinema, que privilegia o gênero crônica no período delimitado pelo título (1896-1932), evidenciando o interesse em revisar o impacto causado pelo novo espetáculo. A partir dessa perspectiva singular, Entre a letra e a tela conecta a literatura, a imprensa e o cinema revisitando o olhar perscrutador dos cronistas, reenviando ao endereçamento do olhar destacado por Caparrós enquanto característica fundamental da crônica por contraposição à notícia.

Através da "retórica do passeio" (RAMOS, 1989), o leitor é convidado a participar de um percurso que, na Introdução, demarca um posicionamento baseado no estudo minucioso da circulação dos modos de percepção do cinematógrafo, expressos em jornais e revistas das áreas geo-culturais recortadas. É um tipo de análise, segundo frisa Miriam Gárate, que toma distância a respeito da aproximação "literatura - cinema" com foco no problema da adaptação, tradicionalmente centrado no jogo entre "fidelidade/infidelidade". Em vez disso, na viagem proposta, aborda-se um fenômeno que é simultaneamente jornalístico, estético e literário, cifrado pela crônica, esse gênero que, pode-se dizer, está na base do processo de formação cultural das naçóes americanas. 
No primero capítulo, "Os escritores-cronistas vão ao cinematógrafo", a forma de modelar os materiais se consolida através do substrato: retórica da viagem, por isso a referência a Ramos e o resgate de vozes centrais como as de Manuel González Prada (Peru), José Martí (Cuba), Manuel Gutierrez Nájera (México), Luis Urbina (México-Espanha), Coelho Neto (Brasil), Olavo Bilac (Brasil), Ruben Darío (Nicaragua), Amado Nervo (México), José Juan Tablada (México-EEUU), Enrique Gómez Carillo (Guatemala-França), João do Rio (Brasil), para mencionar somente alguns. Neles, Gárate observa a recriação de uma estilística que evidencia o deslocamento das crônicas do jornalístico para o literário, daí o entre-lugar, fato que também influi no nascimento de um novo profissional que se consolida ao mesmo tempo que os textos que recriam o impacto suscitado pelo cinematógrafo: o repórter. Destaca-se, nesse sentido, algo que já fora assinalado por outros estudiosos: "a cultura moderna foi 'cinematográfica' antes do cinema"; e talvez seja por esse motivo que o olhar dos cronistas pôde transitar rapidamente do assombro para a reflexão crítica.

Nas crônicas examinadas no primeiro capítulo, acompanhamos as primeiras viagens. "El cinematógrafo" (1896), de Urbina, e "Moléstia de época" (1906), de Olavo Bilac, descrevem a percepção do fenômeno cinematográfico por meio de construçóes discursivas que patenteiam o fascínio exercido, através de referências à "máquina milagrosa" ou ao "aparato prodigioso", deslumbramento que se reitera na crônica do mexicano José Juan Tablada, "México sugestionado: el espectáculo de moda" (1906) e em "En el cine" (1913), de Ramón López Velarde. São essas considerações que desdobram, no segundo capítulo, as reflexôes críticas sobre a linguagem cinematográfica, envolvendo relaçóes com outros gêneros como o teatro e o romance.

Em "Os escritores-críticos se debruçam sobre o cinema", segundo capítulo, Miriam Gárate enfatiza o interesse das primeiras críticas/crônicas pelo cinema narrativo e os diversos modos de lê-lo. Desponta, então, uma questão muito estudada - por isso a recuperaçáo de vários teóricos do cinema, dentre os quais Béla Balázs -, de modo a desvelar como os filmes se constroem e as características da linguagem cinematográfica do período. Como afirma Gárate, "a linguagem cinematográfica transparente (Xavier, 1984) disputa com as outras artes a expressão de uma subjetividade inicialmente reservada [imaginariamente reservada] à palavra" (GÁRATE, 2017, p. 10). As relaçóes com outras práticas artísticas como o teatro são evidencia disso. Em "Da 'estética da ação' à estética da subjetivação", subtítulo de uma das seçôes do segundo capítulo, delineia-se um percurso que elucida as unidades imbricadas na linguagem em processo de construçáo e, simultaneamente, a individualização que afasta o cinema das outras artes: o primeiro plano, o enquadramento, a montagem. A autora contrapóe a visão preconceituosa de Urbina, para quem "o cinema jamais nutrirá a cultura nem aperfeiçoará 
o espírito como o faz o livro", à perspectiva de Torres Bodet, para quem a câmera em A última gargalhada (1924) de Murnau é um "objeto pensante", pois "sonha”, ou, nas palavras de Bálaz, dá forma a um "pensamento ótico". $\mathrm{O}$ contraponto póe em cena o debate entre espetáculo/cultura e refrata as tensões descobertas nessa viagem.

O terceiro capítulo, "O retorno do pleito mimético", recupera as discussóes suscitadas a respeito das transformaçóes nas práticas culturais e sociais produzidas pelo cinema. São relembrados aspectos negativos, percebidos pelos cronistas em relação à possível influência dos filmes que encenam crimes. Para alguns deles, "o efeito pernicioso do novo espetáculo reside na vivacidade das peripécias que mostram [ensinam] os meios e modos de delinquir" (GÁRATE, 2017, p. 99). Daí a proibição aos jovens de frequentar filmes que pudessem levá-los a copiar tais atos, defendida em numerosos escritos. As crônicas revelam em seus títulos essa crença arraigada. "Moralidad, criminología... Lo de siempre. La Razón contra el cinematógrafo" (1919). Repercutem, assim, frases dos próprios jornais, como: "Não acreditamos que a fita torne melhores ou piores os criminosos, mas sim acreditamos que lhes forneça liçóes e os prepare para o delito, dado que a exibição cinematográfica estimula e exalta a imaginação" (La Razón, 1919, apud GÁRATE, 2017, p. 100). Ao mesmo tempo, e com base no mesmo pressuposto mimético, o cinema se torna um meio de instrução através do qual se oferecem uma formação moral, uma escola do bom gosto e uma "educação pelo olhar", como é possível ler na crônica de Horacio Quiroga, "El cine en la escuela: sus apologistas" (Caras y Caretas, 1920). Um fato que transforma algumas salas, como a Fémina, de Lima, em lugares destinados à instrução de garotas e senhoras, fenômeno referido em crônica recuperada por Ricardo Bedoya, estudioso do cinema peruano, citado por Gárate. Por outro lado, o cinema também se torna o espaço da sedução e das paixóes, como atestam alguns escritos de Urbina ("El cine y el delito", 1916), de Lima Barreto ("Amor, cinema e telefone", 1920) ou de Francisco Zamora ("El cine y la moralidad", 1919), todas amostragens dessa dúbia pulsão didática, que se evidencia ainda com mais clareza em "El cine y las costumbres" (1931), do argentino Roberto Arlt, ou nas mençóes aos "problemas entre os sexos" feitas pelo mexicano Carlos Nogueira Hope em "Vanidad de vanidades" (1919).

No capítulo "Os 'latinos' viajam a Hollywood”, a autora aborda a experiência de viagem à cidade cinematográfica por antonomásia como dado significativo que acompanha, entre os anos de 1920-1930, o desenvolvimento da cinematografia estadunidense. Para focar esse aspecto, são escolhidas as narraçóes "Una aventura de amor" (1918), publicada com o pseudônimo de Boy, "Miss Dorothy Phillips, mi esposa" (1919) de Horacio Quiroga, "Che Ferrati, inventor" (1923) de Carlos Nogueira Hope e "Hollywood: novela da vida real” (1932) de Olympio Guilherme. Sustenta Gárate: 
são narrativas que se estruturam ao redor desse motivo [a viagem a Hollywood], assim como una série de outros tópicos comuns: o desvendamento das regras que vigoram nos grandes estúdios bem como de pormenores técnicos e truques de rodagem; o retrato de tipos que se consolidam por esses anos (a flapper, o latino sedutor, o rastaquera); a relação mimética das personagens com modelos propostos pelo cinema (aparência física, atitudes, sentimentos); o enredo amoroso (também ele estreitamente vinculado ao imaginário cinematográfico, o que resulta no entrelaçamento e no revezamento constantes dos registros da 'vida' e do 'filme'); o vínculo afetivo espectador-estrela; o tema do doublê" (GÁRATE, 2017, p. 127).

Nos dois primeiros títulos ("Una aventura de amor" e "Miss Dorothy Phillips) , encena-se uma experiência que propicia o "cancelamento provisório da realidade imediata", estabelecendo a viagem não apenas como deslocamento à capital hollywoodiana, mas como translação da vida diurna à da fantasia provocada pela escuridão da sala e pela construção da linguagem fílmica. Isso permite estabelecer uma analogia com o par vigília/sonho, desenvolvido pela autora com o auxílio das teorizaçóes de Mauerhofer (1966), Jean-Louis Baudry (1970) e Christian Metz (1979).

As personagens que povoam esse conjunto de relatos cristalizam uma galeria de estereótipos que reenvia ao jogo instaurado entre ficcional e "real". Nela, exibem-se os latinos que se lançaram à vida cinematográfica estadunidense: o pobre-diabo representado pelo argentino Guilhermo Grant, o mexicano Federico Granados no papel do latino fogoso, etc. Muitos deles são contemplados nesse quarto capítulo do livro, seguindo um percurso no qual a autora mostra como se configuram nas narrativas as operaçóes que fazem parte da linguagem cinematográfica e implicam uma transferência de códigos para o texto escrito: o recurso gráfico à linha de pontos enquanto sucedâneo do corte/montagem invisível na narrativa de Quiroga, a fórmula fade in para intitular as palavras preliminares no romance de Guilherme, etc. Tais procedimentos são examinados ao longo de "Os latinos viajam a Hollywood" por meio de uma análise que evidencia a perspicácia com que Gárate consegue suturar ambas as linguagens.

Por fim, no quinto e último capítulo do livro, intitulado "Documentários de papel/Crônicas de celuloide", a autora retoma a problemática demarcada inicialmente, com base na hipótese de que durante as últimas décadas do século XIX e princípios do XX, os escritores latino-americanos estabeleceram uma relação estreita e conflituosa com a imprensa tendo na crônica uma de suas manifestaçôes mais significantes. Isso conduz Gárate a enfocar algumas realizaçóes experimentais, entendidas como a cristalização vanguardista das relaçóes exploradas ao longo de seu texto: as crônicas de Antônio de Alcântara Machado reunidas em Pathé-Baby (1926) e o filme de Alberto 
Cavalcanti, Rien que les heures (1926). A autora recupera, então, o eixo principal de seu percurso: a retórica do passeio, sustentando que a aparição do cinema propiciou uma triangulação entre imprensa, crônica e cinema, dando lugar ao nascimento de expressóes híbridas tais como as Atualidades cinematográficas, as Cine-revistas e os Cine-jornais, por um lado, e a adoção de títulos como Kinetoscópio, Cinematógrafo, Vitascópio ou Cinema da vida em colunas cronísticas, por outro. Miriam Gárate também destaca o papel assumido pelo cinema clássico no século XX enquanto "máquina de contar histórias", espécie de permutação ou troca de funçôes desempenhadas pela literatura do século XIX e pelo romance-folhetim. A exposição revela o interesse em desentranhar como se processa uma mudança radical nos textos da época, decorrente de deslocamentos nos âmbitos do jornalismo, da crônica, do romance e do cinema, sinalizando uma ruptura de categorias de gênero na qual primam as tensôes. Por isso, compreende-se que Gárate se pergunte no final do volume, aludindo à imagem da "vendedora de jornais" estampada na capa do livro, e como um modo de ecoar sua reflexão, tentando descobrir o que está além da lente do olho mágico: "Rien que les heures: uma crônica de celuloide?"

\section{Referências bibliográficas}

BUARQUE, Chico. Estorvo. Rio de Janeiro: Companhia das Letras, 1991.

CAPARRÓS, Martín. La crónica: una mirada extrema. Diario La Nación, setembro de 2007. Disponível em: <http://www.lanacion.com.ar/943086-la-cronica-unamirada-extrema>.

GÁRATE, Miriam. Entre a letra e a tela. Literatura, imprensa e cinema na América Latina (1896-1932). Rio de Janeiro: Papéis Selvagens, 2017.

RAMOS, Julio. Desencuentros de la modernidad en América Latina. México: Fondo de Cultura Económica, 1989.

SCHAFFER, M. Pedro Lemebel. La yegua silenciada. Revista Hoy, n. 1072, fevereiro de 1998. Disponível em: <http://www.memoriachilena.cl/archivos2/pdfs/ MC0044778.pdf>.

Hernán Morales. Professor na Universidad Nacional de Mar del Plata. Seus temas de pesquisa são a música e a literatura hispano-americana e brasileira, com uma ampla participação em livros e revistas acadêmicas da área.

E-mail: hhjjmorales@gmail.com

Recebido em: 27/12/2017

Aceito em: 01/03/2018 